\title{
Effective interventions in road traffic accidents among the young and novice drivers of low and middle-income countries: A scoping review
}

\author{
Gyan Gifty ${ }^{\mathrm{a}}$, Sabah Mohd Zubair ${ }^{\mathrm{b}, *}$, Amudha Poobalan ${ }^{\mathrm{c}}$, Kumar Sumit ${ }^{\mathrm{d}}$ \\ ${ }^{a}$ Post graduate student, Master of Public Health program, The Institute of Applied Health Sciences, University of Aberdeen, Scotland, United Kingdom \\ ${ }^{\mathrm{b}}$ Research Assistant, Kasturba Medical College Mangalore, Manipal Academy of Higher Education, India \\ ${ }^{c}$ Programme Lead - Master of Public Health program, The Institute of Applied Health Sciences, University of Aberdeen, Scotland, United Kingdom \\ ${ }^{\mathrm{d}}$ Assistant Professor-Senior scale, Prasanna School of Public, Manipal Academy of Higher Education, India
}

\section{A R T I C L E I N F O}

\section{Keywords:}

Road traffic accidents

Prevention

Intervention

Young adults

\begin{abstract}
A B S T R A C T
Problem considered: Road traffic accident (RTA) is the ninth leading cause of global mortality and are also contributes mortality rates among young adults aged 15-29 years. This paper aims to conduct a comprehensive review to provide evidence of effective interventions of RTA prevention among young adults.

Methods: Three databases, MEDLINE, Embase, and PsychINFO, were searched. Eligible articles were practical behavioural and technological interventions directly affecting young drivers. The quality assessment used critical appraisal tools from the Joanna Briggs Institute (JBI). A narrative approach was used to analyze data of the 1107 articles identified, 17 articles met the inclusion criteria. Six studies used a driving simulator; five studies were educational training interventions; one used an incentive and in-car GPS, and one video-based training. One intervention used a vehicle warning system. A motorcycle simulator intervention and two-hybrid interventions, a pc-training and field training, and a driving simulator and vehicle training were also identified.

Result: The Green Light for Life, a training program, was emphasized as it was a simple intervention, using parent influences to improve injury crash rates by $12.7 \% \mathrm{p}<0.001$. Furthermore, RAPT, a driving simulator, improved gaze in the range of $52.1-70 \% \mathrm{p}<0.001$, and HRT, a motorcycle simulator, showed $0.92, \mathrm{p}<0.001$ proportion of hazard avoidance.

Conclusion: These interventions can provide important leads to be adapted and replicated in various settings globally, to improve RTA outcomes among young adults. Future research can adopt a qualitative approach to determine the willingness of use for these interventions and adherence to current interventions.
\end{abstract}

\section{Introduction}

Road Traffic Accidents (RTAs) can be defined as a collision occurring on the road between objects caused by moving vehicles, for example, cars or motorcycles. ${ }^{1}$ RTAs have emerged as a global health problem and are the ninth leading cause of global mortality, claiming over 1.2 million lives each year. ${ }^{2}$ It is predicted that by 2030 , RTAs will become the seventh leading cause of death globally. ${ }^{3}$ Other indirect health consequences are associated with this growing epidemic. To this end, RTAs have a significant impact on the health and development sector as well as the economy of nations. A loss of approximately $3 \%$ of Gross Domestic Product (GDP) is associated with RTAs. ${ }^{5}$ In the last decade, there has been a $16 \%$ increase in the number of vehicles on the world's roads. ${ }^{6}$ With this increase in the number of vehicles, if the incidence of RTAs remains constant, the number of RTAs will have increased, and even more so if the incidence of RTAs increases.

Young adults and novice drivers are a major reason for the increase in RTAs. ${ }^{11}$ Young adults are defined as individuals between the ages of $15-25$ years as universally defined by the United Nations (UN), ${ }^{12}$ Novice drivers are defined as individuals within this age group who have held their license only for 1-18 months. Individuals in these groups have widely been reported to be high-risk group, engaging in risky driving behaviours that lead to RTAs. ${ }^{13,14}$ Lack of experience, mobile phone usage, speeding and poor hazard perception have been identified as critical factors causing RTAs among young adults. ${ }^{15},{ }^{16},{ }^{17},{ }^{18}$ Due to this, RTAs are reported to be the leading cause of death among young people aged between 15 and 29 years. ${ }^{4,19,22}$

Many Low and Middle-Income Countries (LMIC) going through

\footnotetext{
* Corresponding author.

E-mail address: sharafsabah12@gmail.com (S.M. Zubair).
} 
socio-demographic transitions experience higher RTA death rates. ${ }^{7}$ Countries such as India, are experiencing a significant surge in motorization combined with the expansion of the road network, which has led to RTAs being the sixth leading cause of death in India. ${ }^{8}$ Furthermore, countries like Ghana and Thailand continue to experience high mortality on their roads, ${ }^{9,10}$ highlighting the global nature of the problem.

There has been an insufficient global effort to stop RTAs although the UN General Assembly in 2010 declared 2011-2020 the Global Road Safety Decade. Furthermore, RTAs have been included in the UN Sustainable Development Goals (SDG) in target 3.6 and 11.2. ${ }^{20}$ It has led to increased efforts to collaboratively reduce RTAs globally, with the implementations of programs such as the UN Decade of Action plan. ${ }^{21}$ Current researches so far have mainly been focused on the burden, pattern and causes of road traffic accidents. Due to changes in road infrastructure and young people behaviour in recent times, it is essential to identify key strategies in current times to aid this vulnerable group. The identification of effective strategies for the prevention of RTAs among young adults is of global health importance. A better understanding of effective interventions is needed to inform individuals, organizations, or governments aiming to replicate or implement interventions successfully. The current review has therefore been undertaken, to provide evidence and important leads of effective interventions globally improving RTAs. The review aimed to identify and synthesize evidence of effective interventions for preventing RTAs among young adults and novice drivers in LMIC.

\section{Methods}

A protocol was developed for this scoping review and was approved by the College of Life Sciences and Medicine Ethics and Governance of the University of Aberdeen. Interventions for preventing RTAs among young adults directly were included in this study. Participants were defined as young adults when individuals were between the ages of 15-25 years old to encompass variations across countries in the age at which individuals can obtain a driver's license.

Interventions that assessed only behavioural and technological targeted at individuals who sought to improve 'Road Traffic Accident Outcomes' were included. Comparators were groups with no interventions or existing standard training. The primary outcome measure was any improvement in RTAs among young adults; secondary outcomes included improved driving behaviours that led to improved RTAs such as speeding behaviours, hazard perception, and avoidance.

Qualitative studies were excluded. Studies on infrastructural interventions and Road traffic policies were also excluded as these are beyond the control of young adults. All-Terrain Vehicles (ATVs) interventions were also excluded as these require specific geographical locations that are not generalizable globally.

Three electronic bibliographic databases; MEDLINE, Embase, and PsychINFO were searched as they contained sufficient relevant content. A search strategy was developed using both MeSH terms and text words. Keywords for road traffic accidents, accident prevention and young adults were combined using appropriate Boolean operators, as shown in Supplementary Fig. 1. Besides, manual searches of bibliographies were also carried out on literature included in the review, as well as on systematic reviews identified. Only studies published between the years 2000-2018 were included as young people behaviour and road infrastructure have seen significant changes. There were no geographical limitations or language limitations.

All identified citations were exported to RefWorks, which was used to manage all citations. Titles and abstracts were screened to identify records that met the inclusion criteria for inclusion in the full-text review. Initially, this was carried out independently by two researchers (GG and AP) on a sample of abstracts. Once consistency was achieved, the remaining abstracts were screened by one reviewer (GG). Any disagreements were resolved by discussion and confirmed with the third reviewer (SK). Full text of the potentially eligible articles was obtained for critical appraisal before including in the review.

Data were recorded using a data extraction form, which was developed, piloted, and adapted to capture all relevant information accurately. Two reviewers piloted the form to ensure consistency in data collection. Data items extracted included; study author, publication year, study title, study aims and objectives, methods, intervention description and main findings. A description and example of the data extraction process can be found in supplementary (Fig. 1).

Study quality was assessed using critical appraisal tools from the Joanna Briggs Institute (JBI), ${ }^{23}$ Included studies were; Randomized Controlled Trials (RCT), Quasi-experimental studies, and cohort studies. Due to the variation of studies, JBI assessment tools were deemed appropriate for quality assessment. Studies were judged Good, moderate, or Low quality such that; Good quality when there was less than $10 \%$ bias across each indicator, moderate when there was less than $30 \%$ bias across the indicator and low when there was over $50 \%$ bias across the indicators. The quality assessment was carried out independently by one researcher and cross-checked with the second reviewer to assure the quality of papers.

Data Analysis: Due to observed varied characteristics of studies such as the study designs, sample size and outcome measures, a meta-analysis was not possible. Therefore, a narrative synthesis was carried out. Through this approach, findings from included studies were aggregated into distinctive categories based on the outcome measures reported. Direct measures of RTAs such as RTA incidents and prevalence and RTA crash rates were summarized and tabulated together and indirect outcomes which were shown to reduce road traffic accidents such as speeding behaviour, hazard perception, and driving control were analysed together.

\section{Results}

\subsection{Results of the literature searching}

The systematic search identified 1107 citations (1089 from database searching and 18 from reference search). Around 1026 records were identified after removing duplicates, from which 21 potentially eligible full-text articles were critically appraised. Seventeen studies met the inclusion criteria for this review and were included for analysis. Fig. 1 shows the flow diagram of the literature search process.

\subsubsection{Study characteristics}

The 17 studies included were widely varied geographically, USA (n $=5),{ }^{24-28}$ Netherland $(\mathrm{n}=3),{ }^{29-31}$ France $(\mathrm{n}=1),{ }^{32}$ Israel $(\mathrm{n}=3),{ }^{33-35}$ Estonia $(\mathrm{n}=1),{ }^{36}$ Australia $(\mathrm{n}=2),{ }^{37,38}$ Italy $(\mathrm{n}=1),{ }^{39}$ Thailand $(\mathrm{n}=$ 1). ${ }^{40}$ Most of the studies were controlled trials. However, only five studies were randomized, 11 studies were of quasi-experimental studies design and one cohort study design. Various types of interventions were identified, six studies used a driving simulator, five studies were educational training interventions; one used an incentive and in-car GPS, and one video-based training. One intervention was technology-based using a vehicle warning system. One motorcycle simulator intervention was included. Two interventions were hybrid, a pc-training and field training, and a driving simulator and vehicle training.

Four studies were interventions to improve RTAs directly. ${ }^{26,32,35,40}$ Seven interventions targeted driving behaviours such as speeding, braking lane changes, and lane changes. ${ }^{24,25,29,30,34,36,37}$ Finally, six studies were interventions targeting hazard perception. ${ }^{27,28,31,33,38,39}$ The sample size for the studies was vastly different, ranging from 18 to 130,555 . The studies comprised of both males and females; however, only eight studies distinctly reported the distribution of males and females. Three studies reported a larger male population, and five studies reported a larger female population. Follow up period varied from immediately after the intervention to up to five years after the intervention, with one study measuring the follow-up effect of having the 

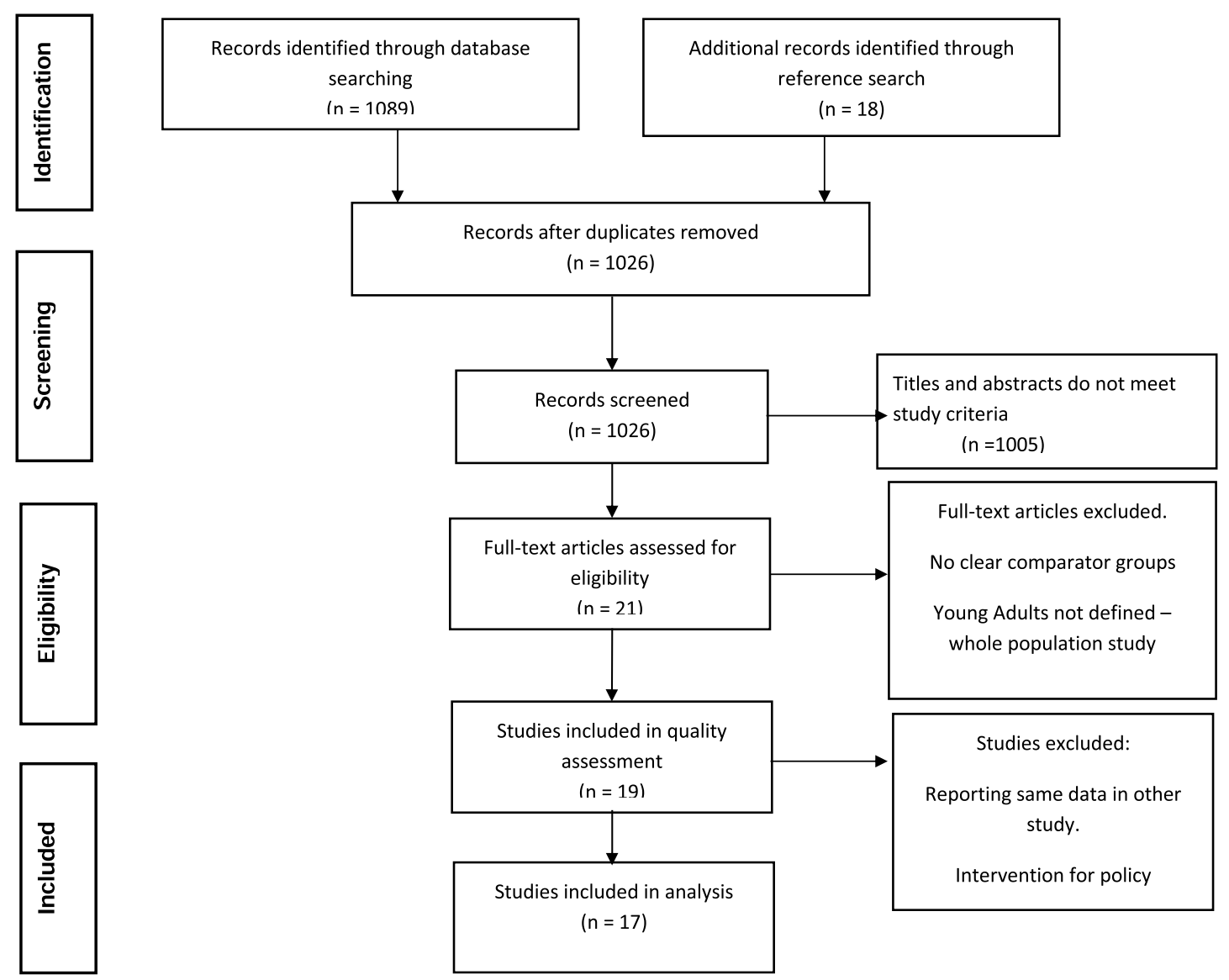

Fig. 1. PRISMA flow diagram for studies included in analysis and reason for exclusion.

intervention removed. ${ }^{29}$ Basic study characteristics are presented in Table 3.

\subsubsection{Quality of studies}

Evaluation of the quality of the studies indicated that 14 studies were of high quality. The remaining three studies had at least one bias indicator. The primary source of bias was the lack of an appropriate description of the randomization methods used. These studies reported randomization; however, they did not provide sufficient details. ${ }^{27-29}$ Furthermore, one study also did not report the method of statistical analysis, which was another bias indicator. ${ }^{27}$ Due to the narrative synthesis of results, it is unlikely that the observed bias had a significant effect on the results.

\subsection{Results of review}

\subsubsection{Improving RTA outcomes}

Table 1 shows the results of four studies that directly measured the improvement of RTAs among young adults. All four interventions were educational training programs. Results are presented for the number of accidents and injuries as well as speeding offences. Of the four studies, a significant reduction in road traffic accidents and injuries was reported in two studies. The Green Light for Life (GLL) program, a training program designed to outline the importance of the accompanied driving phase, by training parents to share hazard perception skills and experiences with young drivers. The implementation of this intervention led to a significant reduction in injury crash rates by $12.7 \%(\mathrm{p}<0.001) .^{35}$

The implementation of the Asia Pacific Honda Training program license (knowledge, skills, and hazard perception) led to a significant effect with odds for injury ratio $(95 \% \mathrm{CI})$ of $0.70(0.53-0.92) .{ }^{40}$ Nonetheless, The Atout Route educational program that provided information to students on the risk of driving under drug or alcohol influences and how to avoid risky behaviours. ${ }^{32}$ Led to reductions in accidents and injuries among the intervention group in the range of $12.1 \%-30.6 \%$. Furthermore, a reduction in the range of $13.8-28.8 \%$ was observed in the number of accidents, driving offences, and speeding offences after the application of a computerized simulation intervention. ${ }^{26}$ However, both these study results did not reach statistical significance.

\subsubsection{Improving driving behaviours}

Table 2 shows the results of seven studies that aimed to improve driving behaviours. These studies employed various methods to improve driving behaviour, including driving simulators, incentives, vehicle warning systems, and hybrid simulators and in-vehicle training.

\subsubsection{Speeding}

One study by using a driving simulator showed that speed exceedance reduced significantly between intervention groups and control groups 2.2 and 4.0, respectively, $\mathrm{p}=0.0010 .^{25}$ Pay-as-you-drive insurance tied insurance premiums to the driving behaviour of the policyholders. When used in combination with in-car GPS technology, the control group stayed constant, with an average of $19.1 \%$ speeding. However, once the incentive was removed from the intervention group, the percentage speeding increased to $20.5 \%$, even higher than the control group. ${ }^{29}$ Training novice drivers using lectures and group work on self-regulation, the odds of exceeding speed limits were approximately half; OR $95 \%$ CI $0.49(0.30-0.80) .{ }^{36}$ The use of Anti-speeding advertisement with positive and negative emotional appeals, found a significant difference in the average speeds after the two anti-speeding advertisements, 43.02, compared to the matched controls $51.24 \mathrm{p}=$ $0.0010 .^{37}$ 
Table 1

Showing results of studies reporting directly on RTA outcomes.

\begin{tabular}{|c|c|c|c|c|c|c|c|c|c|}
\hline $\begin{array}{l}\text { Study ID year and } \\
\text { quality }\end{array}$ & Intervention type/Study Design & \multicolumn{8}{|l|}{ Results } \\
\hline \multirow[t]{16}{*}{$\begin{array}{l}\text { Carcallion L et al., } \\
2005 . \\
\text { Good }\end{array}$} & \multirow[t]{16}{*}{$\begin{array}{l}\text { Educational program - Atout Route } \\
\text { Secondary data analysis, pre-post } \\
\text { intervention. }\end{array}$} & Outcomes & \multicolumn{2}{|c|}{$\begin{array}{l}\text { Intervention } \\
\text { Pre- Test }\end{array}$} & Control & $\begin{array}{l}\text { Intervention } \\
\text { Post Test }\end{array}$ & Control & $\begin{array}{l}\text { Intervention } \\
\text { Variation } \\
(\%)\end{array}$ & $\begin{array}{l}\text { P value for } \\
\text { intervention }\end{array}$ \\
\hline & & Accidents & \multirow{3}{*}{\multicolumn{2}{|c|}{18.9}} & 39.1 & 14.6 & 28.7 & \multirow[t]{3}{*}{-23.1} & 0.206 \\
\hline & & & & & 157.6 & & 142.1 & & \\
\hline & & & & & 292.0 & & 252.4 & & \\
\hline & & Fatal & \multicolumn{2}{|c|}{1.9} & 4.5 & 1.7 & 3.1 & -12.1 & \\
\hline & & \multirow[t]{2}{*}{ Accidents } & & 8.3 & & 7.6 & & \\
\hline & & & & & 17.7 & & 14.5 & & \\
\hline & & \multirow[t]{3}{*}{ Deaths } & \multirow{3}{*}{\multicolumn{2}{|c|}{2.2}} & 5.2 & 1.9 & 3.4 & \multirow[t]{3}{*}{-14.2} & \\
\hline & & & & & 9.3 & & 8.6 & & \\
\hline & & & & & 19.8 & & 15.8 & & \\
\hline & & Severe & \multicolumn{2}{|c|}{9.3} & 18.0 & 6.5 & 11.9 & -30.6 & \\
\hline & & \multirow[t]{2}{*}{ Injuries } & & 40.5 & & 28.9 & & \\
\hline & & & & & 72.5 & & 53.8 & & \\
\hline & & Light & \multicolumn{2}{|c|}{18.8} & 35.0 & 15.7 & 26.7 & -16.5 & \\
\hline & & \multicolumn{3}{|l|}{ Injuries } & 190.6 & & 168.8 & & \\
\hline & & & & & 326.8 & & 287.6 & & \\
\hline \multirow[t]{4}{*}{$\begin{array}{l}\text { Ekeh et al., } 2013 \\
\quad \text { Good }\end{array}$} & \multirow[t]{4}{*}{$\begin{array}{l}\text { Computerised driver - safety education } \\
\text { program }\end{array}$} & Outcome & & \multicolumn{2}{|c|}{$\begin{array}{l}\text { Intervention ( } \mathrm{n} \\
=16)\end{array}$} & Control $(\mathrm{n}=19)$ & $\begin{array}{l}\text { Difference } \\
(\%)\end{array}$ & $P$ value & \\
\hline & & \multirow{2}{*}{$\begin{array}{l}\text { No. Accidents } \\
\text { Driving incidents }\end{array}$} & & 1 & & 4 & -14.9 & 0.6 & \\
\hline & & & & 3 & & 9 & -28.6 & 0.1516 & \\
\hline & & $\begin{array}{l}\text { Speeding } \\
\text { offences }\end{array}$ & & 2 & & 5 & -13.8 & 0.415 & \\
\hline $\begin{array}{l}\text { Toledo et al., } 2011 \\
\text { Good }\end{array}$ & $\begin{array}{l}\text { Training program- Green Light for Life } \\
\text { (GLL) }\end{array}$ & Outcome & & $\begin{array}{l}\text { Intervent } \\
(44,454)\end{array}$ & & Control $(86,111)$ & $\begin{array}{l}\text { Difference, } \\
\text { p value }\end{array}$ & $\mathrm{p}$ value & \\
\hline & Secondary data analysis & Injury Car & & 1093 & & 2426 & -35.9 & $<0.001$ & \\
\hline & & Crashes & & & & & $(-12.7 \%)$ & & \\
\hline & & $\begin{array}{l}\text { Injury car crash } \\
\text { rate per } 10,000\end{array}$ & & 245.9 & & 281.7 & & & \\
\hline Woratanat et al., & Motorcycle Training program- Asia- & Outcome & & & Inter & rvention ( $\mathrm{n}=2729$ ) & Contr & $\operatorname{rol}(n=2963)$ & \\
\hline 2013 & Pacific Honda training program & Number of & & & $99(3$ & 3.63) & 140( & $(4.72)$ & \\
\hline Good & Secondary Data Analysis & injuries & & & & & & & \\
\hline & & Odds Ratio (95\% & (CI) & & 0.70 & $(0.53-0.92)$ & Refer & rence group & \\
\hline
\end{tabular}

\subsubsection{Driving control}

Usage-Based Insurance (UBI) interfaces with Dutch insurance companies, aimed to reduce insurance costs by policyholders adopting safer driving styles. The intervention group performed better than the control group and spent less time braking, accelerating, and cornering $0.025 \mathrm{p}$ $<0.001,0.26 \mathrm{p}=0.002$, and $0.0 \mathrm{p}=0.014$, respectively. ${ }^{30}$ One study found that implementing a vehicle warning system to evaluate crash avoidance led to significant improvement in forwarding collision avoidance, and lateral drift into unoccupied lanes. The intervention group logged fewer warnings 107, 1,022, as compared to the control group 456, 5972. These differences were statistically significant $\mathrm{p}<$ 0.001 and $\mathrm{p}=0.005$ respectively. ${ }^{24}$ Collision avoidance was also found to improve using a driving simulator significantly; among the intervention group, mean (SD) was 0.83 (1.5) as compared to the control 0.63 (1.9), $\mathrm{p}<0.001 .{ }^{25} \mathrm{~A}$ simulative workshop intervention found that young drivers in the intervention group braked more often and were less prone to headway events. However, only headway variance reached statistical significance, as the intervention group had a mean (SD)of $0.31(0.11)$ and the control group $0.37(0.06) .{ }^{34}$

\subsubsection{Improving hazard perception}

Table 3 shows the results of six studies that aimed to improve RTAs by improving the hazard perception of young adults and novice drivers. These studies employed various methods to improve driving behaviour, including driving simulators with in-car technology, pc-based training, educational training, motorcycle simulator, and video-based training. Across all interventions, hazard perception was reported to increase significantly in the intervention group as compared to the control group. Two studies used the Risk Awareness and Perception Training program (RAPT) ${ }^{27,28}$ Various versions of this program exist with the main focus on hazard avoidance. These studies found significant improvement in gaze behaviour among the intervention group as compared to the control group within the range of $52.1-70 \%$ in the intervention group and 28.1 and $42.5 \%$ in control. All differences between the groups were statistically significant, with an average difference of $26.2 \%$. This intervention was highly effective, as reported results were tested in field studies.

One study reported a better proportion of hazards avoided in the intervention group; 0.92 as compared to four control groups ranging from 0.78 to 0.87 , using the Honda Riding Trainer (HRT), a motorcycle simulator to improve hazard perception. This result was highly statistically significant $\mathrm{p}<0.0000010 .{ }^{39}$ One study used hazard perception commentary training, which involved verbal instruction from the expert instructor or active searches of 'what happens next' exercises. This study found that all training groups significantly improved their hazard perception time as compared to the control group. However, the full training package - (what happens next and hybrid commentary training) led to the most significant improvement with a mean time reduction of $4.32 \mathrm{~s}$, a difference of 4.12 from the control group. ${ }^{38}$

The Act and Anticipate Hazard Perception Training (AAHPT) was implemented based on exposing young drivers to real-life traffic hazards, to enhance their ability to anticipate hazards. This study found that novice drivers with the active and hybrid mode of intervention detected more hazardous events than drivers in the control group; mean (SD) 6.4 (2.3), 7.9(1.5), and 4.8 (3.2), respectively. ${ }^{33}$ One study utilized a driving simulator with in-car technology to observe the gaze behaviour of novice drivers, which falls in the road centre. ${ }^{31}$ This study found that even with obstructed views, the gaze of young drivers in the intervention group improved from a mean (SD) of 46.2 (9.2) to 63.3 (13.9) whereas the control group stayed constant at an average of 43.4. Performance in the unobstructed view is even better, improving from 52.7 (12.9) to 72.1 (14.1). 
Table 2

Showing results of seven studies reporting on driving behaviours, including speed and driving control.

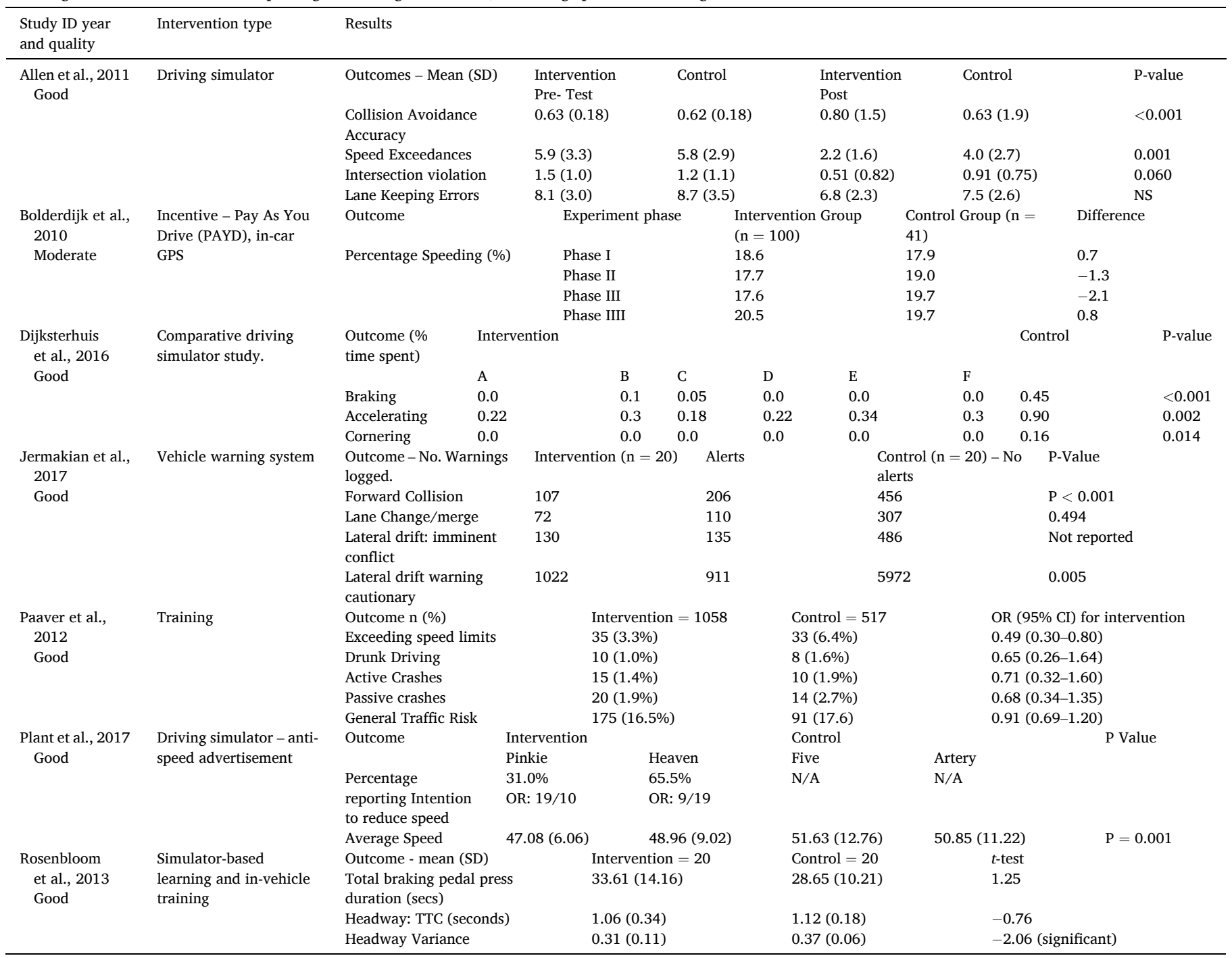

\section{Discussion}

This scoping review identified 17 interventions outlining various interventions for reducing RTAs among young adults. Fourteen of these studies were of good quality and only three were of moderate quality. Therefore, this review provides evidence that RTAs can be reduced among young adults and novice drivers using a wide range of simple interventions ranging from simulators and training to incentives. The most accessible intervention to replicate in this review was the GLL program. This program utilises parents, who have been identified as key factors affecting young driver's behaviour to reduce crash rates. ${ }^{41,42}$ This study used a sample size of 130,565 and a follow-up period of 24 months to significantly quantify direct reductions in road traffic crash rates among young adults. This intervention was effective as studies have shown that young drivers lack experience and competence in the first year of licensure. ${ }^{15,41}$ Therefore, designing an intervention to extend the accompanied driving phase yielded highly significant results as parents can train young drivers to be more cautious on the road. Research shows that parental driving influences when positive directly positively impact young driver behaviour, ${ }^{43,44}$ not only with respect to driving but in other areas such as substance abuse. ${ }^{45,46}$ If good driving behaviours are practised over a long period, they become second nature, which leads directly to reduce crashes, as shown by this study.
It is essential to note that although the primary outcome measure for the GLL program was the crash rates among young adults, this effect was achieved through developing good driving behaviours among young adults primarily through hazard perception. Additionally, six studies identified used various methods to improve hazard perception. Four of them reported highly significant improvement in hazard perception. The most effective interventions, however, were the RAPT and HRT. These led to improved hazard perception and avoidance for both young drivers and motorcyclists. A high correlation has been reported between improving hazard perception skills among young people and improved road traffic accidents. ${ }^{47-50}$ Therefore, improving hazard perception will lead to improved RTAs.

The studies presented in this review were mainly located in Europe, America, and Asia. Although presenting effective interventions among young adults, care must be taken in the generalisability of these results in different settings due to cultural differences and young driver behaviours. For example, the GLL program in Israel reported selection bias as Ultra-Orthodox Jews and the Arab population does not tend to participate in the program. ${ }^{35}$ Given that the LMICs face a higher burden of RTAs, it is vital to consider the practicality of implementing these interventions in such settings. Due to the abundance of both two and four-wheeler vehicles in these settings, this research aggregated findings for both vehicle types. However, countries of low and middle income 
Table 3

Showing the results of six studies reporting on improving hazard perception.

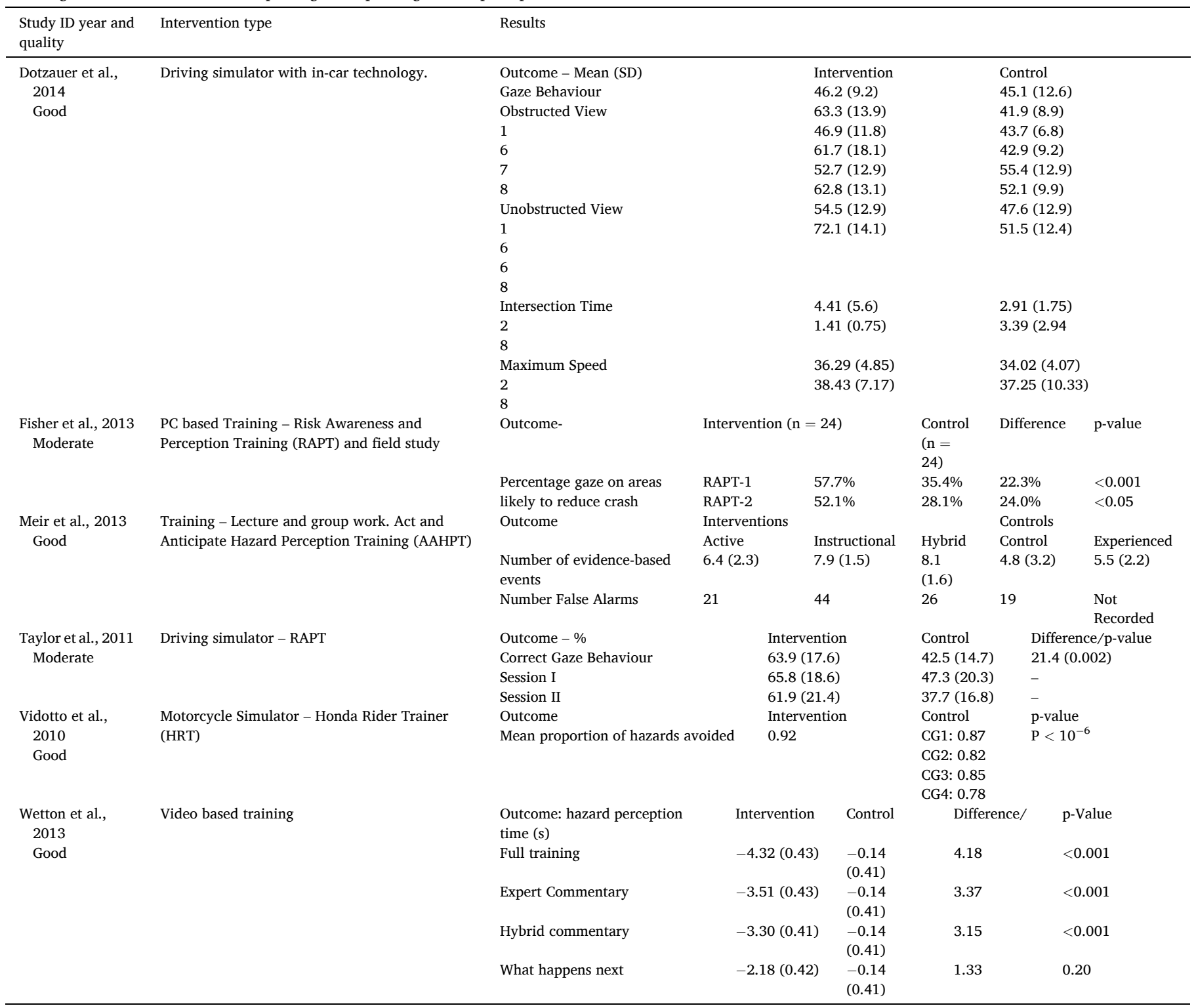

generally lack the resources and infrastructure to implement the high-cost interventions. ${ }^{51}$ Careful consideration of the cost-effectiveness of these interventions must be considered before implementation. The behavioural and technological interventions presented in this review were designed to directly influence young driver behaviours to improve road traffic outcomes-various literature report on infrastructural and legislative initiatives, ${ }^{52-54}$ to reduce RTAs. Unfortunately, legislative initiatives are stifled by bureaucratic procedures and may find implementation could take years. ${ }^{55}$ Infrastructural improvements, although beneficial, will not have the desired effect of improving RTAs in young adults if the road users do not have the knowledge or skills to make better choices on the road. The interventions described in this review can be easily implemented across various communities and schools as well as on national levels and as was evident, the effect can quickly be monitored and quantified over time.

Practical Implications:This is the first review that has assessed interventions specifically among young adults and novice drivers, who are the most vulnerable group for road traffic accidents. RTA prevention interventions predominantly focus on children or older adults, leaving this vulnerable group neglected. Hence this review bridges the gap in the evidence for this age group.

Furthermore, this review maps out interventions reporting on speeding behaviours, driving control and hazard perception, selection based on the population and intervention type must all be considered before replicate any of the interventions. Future research should adopt a qualitative approach to determine the willingness of the use these intervention types among young people and adherence to current interventions. This is especially important as a vast majority of these interventions require voluntary participation; therefore, a qualitative approach will engage the young people and ensure more straightforward implementation in various communities.

There were some limitations with this review, which must be considered when evaluating the results presented-defining the publication year between 2000 and 2018 means that all the effective interventions identified before that were excluded from the study. Nonetheless, this review aimed to give a more current view of things to account for changes in motorization, infrastructure and young adult behaviours. Only studies with clearly defined comparator groups were included in the review. This means that other effective interventions may have been excluded. However, including such studies would have 
been detrimental to the quality of evidence reported as comparator groups give a much clearer measure of effect. Given the timeframe for this review, three significant databases were searched. There are a large number of successful interventions published in Grey Literature, but this study sought to highlight interventions that have been subject to academic rigour. Some studies reported improvements in outcome measures, which did not reach statistical significance which can be attributed to the small sample sizes used in some reviews.

\section{Conclusion}

The current systematic review provided significant leads and evidence from 17 interventions for improving RTAs directly and indirectly through various intervention modes. The GLL, RAPT, and HRT programs have been identified as effective interventions among young adults. Notwithstanding, care must be taken when implementing an intervention to various country settings due to variability in cultures and young adult behaviours. Interventions that are cheap and easy to replicate must be designed in order to reach the most vulnerable individuals in regions where the issue is more common. Organizations and policymakers should consider the appropriate intervention which is suitable for their setting. Future research should take a qualitative approach to determine the willingness of use and adherence to current interventions.

\section{Declaration of competing interest}

None.

Acknowledgements

None.

\section{Appendix A. Supplementary data}

Supplementary data to this article can be found online at https://doi. org/10.1016/j.cegh.2021.100865.

\section{Funding}

None.

\section{Authors contribution}

Gyan Gifty and Kumar Sumit: Conceptualization, Methodology, Software GyanGifty: Data curation, Writing- Original draft preparation. Amudha Poobalan: Visualization, Investigation. Kumar Sumit and Amudha Poobalan: Supervision: Kumar Sumit and GyanGifty: Software, Validation.: Sabah Mohd Zubair: Writing- Reviewing and Editing.

\section{References}

1 Jha N, Srinivasa D, Roy G, Jagdish S, Minocha R. Epidemiological study of road traffic accident cases: a study from South India. Indian J Community Med. 2004;29(1): 20-24.

2 Ameratunga S, Hijar M, Norton R. Road-traffic injuries: confronting disparities to address a global-health problem. The Lancet. 2006;367(9521):1533-1540.

3 Mathers CD, Loncar D. Updated Projections of Global Mortality and Burden of Disease, 2002-2030: Data Sources, Methods and Results. Geneva: World Health Organization; 2005.

4 Odero W, Garner P, Zwi A. Road traffic injuries in developing countries: a comprehensive review of epidemiological studies. Tropical Medicine \& International Health. 1997;2(5):445-460.

5 World Health Organization. Global Status Report on Road Safety 2015. World Health Organization; 2015.

6 Peden M, Scurfield R, Sleet D, et al. No Title. World Report on Road Traffic Injury Prevention. 2004.

7 Amo T, Meirmanov S. The epidemiology of road traffic accident (RTA) in Ghana, 2001-2011. Life Science Journal. 2014;11(9).

8 Ruikar M. National statistics of road traffic accidents in India. Journal of Orthopedics, Traumatology and Rehabilitation. 2013;6(1):1.
9 Aidoo EN, Amoh-Gyimah R, Ackaah W. The effect of road and environmental characteristics on pedestrian hit-and-run accidents in Ghana. Accident Analysis \& Prevention. 2013;53:23-27.

10 Suriyawongpaisal P, Kanchanasut S. Road traffic injuries in Thailand: trends, selected underlying determinants and status of intervention. Injury Control Safe Promot. 2003;10(1-2):95-104.

11 Al Reesi H, Al Maniri A, Adawi SA, Davey J, Armstrong K, Edwards J. Prevalence and characteristics of road traffic injuries among young drivers in Oman, 2009-2011. Traffic injury prevention. 2016;17(5):480-487.

12 Curtain R. Youth and employment: a public policy perspective. Development Bulletin. 2001;55(1):7-11.

13 Scott-Parker B, Hyde MK, Watson B, King MJ. Speeding by young novice drivers: what can personal characteristics and psychosocial theory add to our understanding? Accident Analysis \& Prevention. 2013;50:242-250.

14 World Health Organization. Global Status Report on Road Safety 2013: Supporting a Decade of Action: Summary. 2013.

15 Mayhew DR, Simpson HM, Pak A. Changes in collision rates among novice drivers during the first months of driving. Accident Analysis \& Prevention. 2003;35(5): 683-691.

16 Underwood G. Visual attention and the transition from novice to advanced driver. Ergonomics. 2007;50(8):1235-1249.

17 Scott-Parker B, King MJ, Watson B. The psychosocial purpose of driving and its relationship with the risky driving behaviour of young novice drivers. Transportation research part F: traffic psychology and behaviour. 2015;33:16-26.

18 Trivedi A, Rawal D. Prevalence of road traffic accidents and driving practices among young drivers. Age. 2011;61:31-39.

19 World Health Organization. Global Status Report on Road Safety 2015. World Health Organization; 2015.

20 United Nations. Sustainable Development Goals Report 2016. UN; 2016.

21 World Health Organization. Saving Millions of Lives: Decade of Action for Road Safety 2011-2020. 2011.

22 Moher D, Liberati A, Tetzlaff J, Altman DG. Preferred reporting items for systematic reviews and meta-analyses: the PRISMA statement. Ann Intern Med. 2009;151(4): 264-269.

23 Joanna Briggs Institute, Joanna Briggs Institute. Critical appraisal tools. University of Adelaide; 2016. Adelaide, Australia Available from http://joannabriggs.org/resea rch/critical-appraisal-tools.html.

24 Jermakian JS, Bao S, Buonarosa ML, Sayer JR, Farmer CM. Effects of an integrated collision warning system on teenage driver behavior. J Saf Res. 2017;61:65-75.

25 Allen W, Park G, Terrace S, Grant J. Detecting Transfer of Training through Simulator Scenario Design: A Novice Driver Training Study. 2011.

26 Ekeh AP, Herman K, Bayham D, Markert R, Pedoto M, McCarthy MC. Pilot evaluation of the short-term effect of driving simulation on novice adolescent drivers. Journal of trauma and acute care surgery. 2013;75(1):83-87.

27 Fisher DL, Pollatsek AP, Pradhan A. Can novice drivers be trained to scan for information that will reduce their likelihood of a crash? InjPrev. 2006 June 01;12 (Suppl 1):i25-i29.

28 Taylor T, Masserang K, Pradhan A, et al. Long-term Effects of Hazard Anticipation Training on Novice Drivers Measured on the Open Road Proc Int Driv Symp Hum Factors Driv Assess Train Veh Des. vol. 2011. 2011:187-194.

29 Bolderdijk JW, Knockaert J, Steg E, Verhoef ET. Effects of Pay-As-You-Drive vehicle insurance on young drivers' speed choice: results of a Dutch field experiment. Accident Analysis \& Prevention. 2011;43(3):1181-1186.

30 Dijksterhuis C, Lewis-Evans B, Jelijs B, Tucha O, de Waard D, Brookhuis K. In-car usage-based insurance feedback strategies. A comparative driving simulator study. Ergonomics. 2016;59(9):1158-1170.

31 Dotzauer M, De Waard D, Caljouw SR, Pöhler G, Brouwer WH. Behavioral adaptation of young and older drivers to an intersection crossing advisory system. Accident Analysis \& Prevention. 2015;74:24-32.

32 Carcaillon LI, Salmi LR. Evaluation of a program to reduce motor-vehicle collisions among young adults in the county of Landes, France. Accident Analysis \& Prevention. 2005;37(6):1049-1055.

33 Meir A, Borowsky A, Oron-Gilad T. Formation and evaluation of act and anticipate hazard perception training (AAHPT) intervention for young novice drivers. Traffic injury prevention. 2014;15(2):172-180.

34 Rosenbloom T, Eldror E. Effectiveness evaluation of simulative workshops for newly licensed drivers. Accident Analysis \& Prevention. 2014;63:30-36.

35 Toledo T, Lotan T, Taubman-Ben-Ari O, Grimberg E. Evaluation of a program to enhance young drivers' safety in Israel. Accident Analysis \& Prevention. 2012;45: 705-710.

36 Paaver M, Eensoo D, Kaasik K, Vaht M, Mäestu J, Harro J. Preventing risky driving: a novel and efficient brief intervention focusing on acknowledgement of personal risk factors. Accident Analysis \& Prevention. 2013;50:430-437.

37 Plant BR, Irwin JD, Chekaluk E. The effects of anti-speeding advertisements on the simulated driving behaviour of young drivers. Accident Analysis \& Prevention. 2017; 100:65-74.

38 Wetton MA, Hill A, Horswill MS. Are what happens next exercises and self-generated commentaries useful additions to hazard perception training for novice drivers? Accident Analysis \& Prevention. 2013;54:57-66.

39 Vidotto G, Bastianelli A, Spoto A, Sergeys F. Enhancing hazard avoidance in teennovice riders. Accident Analysis \& Prevention. 2011;43(1):247-252.

40 Woratanarat P, Ingsathit A, Chatchaipan P, Suriyawongpaisal P. Safety riding program and motorcycle-related injuries in Thailand. Accident Analysis \& Prevention. 2013;58:115-121. 
41 Simons-Morton B. Parent involvement in novice teen driving: rationale, evidence of effects, and potential for enhancing graduated driver licensing effectiveness. $J$ Saf Res. 2007;38(2):193-202.

42 Taubman-Ben-Ari O. Attitudes toward accompanied driving: the views of teens and their parents. Transportation research part F: traffic psychology and behaviour. 2010;13 (4):269-276.

43 Simons-Morton BG, Hartos JL. How well do parents manage young driver crash risks? J Saf Res. 2003;34(1):91-97.

44 Simons-Morton BG, Ouimet MC, Catalano RF. Parenting and the young driver problem. Am J Prev Med. 2008;35(3):S294-S303.

45 Dishion TJ, Loeber R. Adolescent marijuana and alcohol use: the role of parents and peers revisited. Am J Drug Alcohol Abuse. 1985;11(1-2):11-25.

46 Wood MD, Read JP, Mitchell RE, Brand NH. Do parents still matter? Parent and peer influences on alcohol involvement among recent high school graduates. Psychology of Addictive Behaviors. 2004;18(1):19.

47 Boufous S, Ivers R, Senserrick T, Stevenson M. Attempts at the practical on-road driving test and the hazard perception test and the risk of traffic crashes in young drivers. Traffic injury prevention. 2011;12(5):475-482.

48 Cheng AS, Ng TC, Lee HC. A comparison of the hazard perception ability of accident involved and accident-free motorcycle riders. Accident Analysis \& Prevention. 2011;43 (4):1464-1471.
49 Darby P, Murray W, Raeside R. Applying online fleet driver assessment to help identify, target and reduce occupational road safety risks. SafSci. 2009;47(3): 436-442.

50 Wells P, Tong S, Grayson G, Jones E. Cohort II-A Study of Learner and New DriversVolume 1-main Report, Volume 2-questionnaires and Data Tables. Road Safety Research Report; 2008.

51 Staton C, Vissoci J, Gong E, et al. Road traffic injury prevention initiatives: a systematic review and metasummary of effectiveness in low and middle-income countries. PLoS One. 2016;11(1), e0144971.

52 Zimmerman K, Jinadasa D, Maegga B, Guerrero A. Road traffic injury on rural roads in Tanzania: measuring the effectiveness of a road safety program. Traffic injury prevention. 2015;16(5):456-460.

53 Nadesan-Reddy N, Knight S. The effect of traffic calming on pedestrian injuries and motor vehicle collisions in two areas of the eThekwini Municipality: a before-andafter study. South African Medical Journal. 2013;103(9):621-625.

54 Passmore J, Tu NTH, Luong MA, Chinh ND, Nam NP. Impact of mandatory motorcycle helmet wearing legislation on head injuries in Viet Nam: results of a preliminary analysis. Traffic injury prevention. 2010;11(2):202-206.

55 Brynard P. The policy gap in South Africa. Journal of Public Administration. 2007;42 (3):357-365. 